\title{
Enhanced allostimulatory activity of host antigen-presenting cells in old mice intensifies acute graft-versus-host disease
}

\author{
Rainer Ordemann, ${ }^{1}$ Raymond Hutchinson, ${ }^{1}$ Jeffrey Friedman, ${ }^{2}$ Steven J. Burakoff, ${ }^{2}$ \\ Pavan Reddy, ${ }^{1}$ Ulrich Duffner, ${ }^{1}$ Thomas M. Braun, ${ }^{1}$ Chen Liu, ${ }^{3}$ Takanori Teshima, ${ }^{1}$ \\ and James L.M. Ferrara ${ }^{1}$
}

\begin{abstract}
${ }^{1}$ Blood and Marrow Transplant Program, Division of Hematology and Oncology, Department of Internal Medicine and Department of Pediatrics, University of Michigan Cancer Center, Ann Arbor, Michigan, USA

${ }^{2}$ Department of Pediatric Oncology, Dana Farber Cancer Institute, Boston, Massachusetts, USA

${ }^{3}$ Department of Pathology, Immunology and Laboratory Medicine, University of Florida, Gainesville, Florida, USA

Address correspondence to: James L.M. Ferrara, University of Michigan Cancer Center,

1500 East Medical Center Drive, Ann Arbor, Michigan 48109-0942, USA.

Phone: (734) 615-1340; Fax: (734) 647-9271; E-mail: ferrara@umich.edu.
\end{abstract}

Received for publication December 6, 2001, and accepted in revised form March 13, 2002.

Older bone marrow transplantation (BMT) recipients are at heightened risk for acute graft-versushost disease (GVHD) after allogeneic BMT, but the causes of this association are poorly understood. Using well-characterized murine BMT models we have explored the mechanisms of increased GVHD in older mice. GVHD mortality, morbidity, and pathologic and biochemical indices were all worse in old recipients. Donor $T$ cell responses were significantly increased in old recipients both in vivo and in vitro when stimulated by antigen-presenting cells (APCs) from old mice, which also secreted more TNF- $\alpha$ and IL-12 after LPS stimulation. In a B6 $\rightarrow$ B6D2F1 model, CD4 ${ }^{+}$donor $\mathrm{T}$ cells but not $\mathrm{CD8}^{+} \mathrm{T}$ cells mediated more severe GVHD in old mice. We confirmed the role of aged APCs in GVHD using B6D2F1 BM chimeras created with either old or young BM. Four months after chimera creation, allogeneic BMT from B6 donors caused significantly worse GVHD in old BM chimeras. APCs from these mice also stimulated greater responses from allogeneic cells in vitro. These data demonstrate a hitherto unsuspected mechanism of amplified donor $\mathrm{T}$ cell responses by aged allogeneic host APCs that increases acute GVHD in aged recipients in this BMT model.

J. Clin. Invest. 109:1249-1256 (2002). DOI:10.1172/JCI200214793.

\section{Introduction}

Allogeneic bone marrow transplantation (BMT), an important therapy for a number of hematologic diseases, is complicated by graft-versus-host disease (GVHD). In its acute phase, GVHD is manifest as an inflammatory process, with activation of proinflammatory cytokine cascades, immune effector cells, and target tissue damage $(1,2)$. Multiple cellular populations and cytokines interact in a complex process that ultimately results in apoptotic injury in target organs (skin, gut, liver) and systemic disease. During acute GVHD, activated donor $\mathrm{T}$ cells secrete Th1 cytokines, including IFN- $\gamma$, in response to host antigens $(3,4)$. Shlomchik and colleagues have shown that hostderived antigen-presenting cells (APCs) play a key role in the initiation of acute GVHD (5).

Advanced age of the BMT recipient is an important determinant of GVHD severity. In one Seattle study, GVHD (grades II-IV) was $20 \%$ in patients less than 20 years of age, $30 \%$ in patients between $30-45$ years of age, and $79 \%$ in patients greater than 50 years of age (6). The increased risk of GVHD, together with the toxicity of conditioning among patients greater than 60 years old, often excludes older patients from consideration for allogeneic BMT. The mechanism for this association is still poorly understood, although several possibilities have been suggested, including thymic involution and impaired ability of host defenses, increased bacterial and viral colonization of the gastrointestinal (GI) tract, and declining repair processes in damaged tissues with age. We have investigated the mechanisms by which advanced recipient age increases GVHD in murine BMT models of acute GVHD. We confirm and extend previous studies of acute GVHD in experimental models (7) and demonstrate a previously unsuspected mechanism by which APCs from aged recipients exhibit increased allostimulatory capacity that results in enhanced activation of donor $\mathrm{T}$ cells and subsequent amplification of clinical disease.

\section{Methods}

BMT. Female C57BL/6 (B6, H-2 $\left.2^{\mathrm{b}}, \mathrm{CD} 45.2^{+}\right), \mathrm{B} 6 \mathrm{D} 2 \mathrm{~F} 1$ $\left(\mathrm{H}-2^{\mathrm{b} / \mathrm{d}}, \mathrm{CD} 45.2^{+}\right)$, B6SJLF1 $\left(\mathrm{H}-2^{\mathrm{b} / \mathrm{s}}\right)$, B10.BR $\left(\mathrm{H}-2^{\mathrm{k} / \mathrm{k}}\right)$, and CBA $\left(\mathrm{H}-2^{\mathrm{k} / \mathrm{k}}\right)$ mice were purchased from The Jackson Laboratory (Bar Harbor, Maine, USA). B6.Ly5.2 $\left(\mathrm{H}-2^{\mathrm{b}}, \mathrm{CD} 45.1^{+}\right)$mice were purchased from Frederick Cancer Research Facility (Frederick, Maryland, USA). Mice were transplanted according to a standard protocol 
described previously (8). Briefly, mice received 7.5 or 11 Gy total body irradiation (TBI, ${ }^{137} \mathrm{Cs}$ source), split into two doses separated by 3 hours to minimize GI toxicity. BM cells $\left(5 \times 10^{6}\right)$ plus $2 \times 10^{6}$ nylon wool-purified splenic $\mathrm{T}$ cells from either allogeneic or syngeneic donors cells were resuspended in $0.25 \mathrm{ml}$ of Leibovitz medium L-15 (GIBCO BRL; Life Technologies Inc., Carlsbad, California, USA) and injected intravenously into recipients on day 0 . For engraftment experiments, B6.Ly5.2 (H-2 $\left.2^{\mathrm{b}}, \mathrm{CD} 45.1^{+}\right)$animals were used as donors. In some cases, T-cell depletion of BM (using antiThy $1.2 \mathrm{mAb}$ and rabbit complement) was performed.

To create $\mathrm{BM}$ chimeras, young $\mathrm{B} 6 \mathrm{D} 2 \mathrm{~F} 1$ mice $(2$ months old) received 11 Gy TBI to eradicate host hematopoiesis. BM cells $\left(5 \times 10^{6}\right)$ from young $(2$ months) or old (18 months) syngeneic mice were injected intravenously into recipients on day 0 . After 3 months of hematopoietic engraftment and APC repopulation, these chimeric mice were used as recipients.

Clinical and histologic assessment of GVHD. Survival was monitored daily, and GVHD clinical scores were assessed weekly by a scoring system incorporating five clinical parameters: weight loss, posture (hunching), activity, fur texture, and skin integrity, as described (9). Individual mice were ear-tagged and graded weekly on a scale from 0 to 2 for each criterion (maximum score 10). GVHD was also assessed by detailed histopathologic analysis of the small (ileum) and large (ascending) intestines using a semiquantitative scoring system as described previously (10).

Cell cultures. All culture media reagents were purchased from Life Technologies Inc. Cells were plated in 96-well flat-bottomed Falcon plates (Becton Dickinson and Co., Lincoln Park, New Jersey, USA) at a concentration of $2 \times 10^{5}$ cells/well with $1 \times 10^{5}$ irradiated $(20 \mathrm{~Gy}$ ) peritoneal cells lavaged from either naive B6D2F1 (allogeneic) or B6 (syngeneic) animals and maintained in a humidified atmosphere with $7.5 \% \mathrm{CO}_{2}$. Supernatants were collected after 48 hours for IL-2 and after 62 hours for IFN- $\gamma$ measurement. Dendritic cells (DCs) were generated by culturing BM cells with $10 \mathrm{ng} / \mathrm{ml}$ GM-CSF and $10 \mathrm{ng} / \mathrm{ml} \mathrm{IL-} 4$ at $1 \times 10^{6}$ cells/ml $(11,12)$. On day 5 of culture, DCs were enriched by density-gradient centrifugation using 14.5\% metrizamide (Sigma Chemical Co., St. Louis, Missouri, USA). DC fractions were removed from the low-density interface, washed twice, and incubated with anti-CD11c (N418) MicroBeads for magnetic cell separation with an AutoMACS system (Miltenyi Biotec, Bergisch Gladbach, Germany). The purity of the DC suspension was greater than $95 \%$ as determined by dual positivity for MHC class II and CD11c. For studies of TNF- $\alpha$ and IL-12 p40 secretion, $1 \times 10^{5}$ DCs per well were plated in 96-well Falcon plates with $0.1 \mu \mathrm{g} \mathrm{LPS} / \mathrm{ml}$ for 4 or 24 hours.

Cytokine ELISA. Concentrations of IFN- $\gamma$, IL-2, and IL-12 p40 were measured by sandwich ELISA as described (BD Pharmingen, San Diego, California, USA). (TNF- $\alpha$ ) Quantikine; R\&D Systems Inc., Minneapolis, Minnesota, USA) (13).

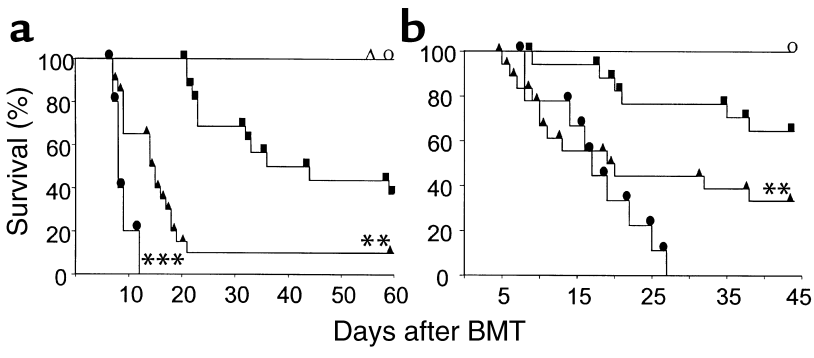

Figure 1

Reduced survival and increased severity of GVHD in older recipients after allogeneic BMT. (a) Very old (filled circles, $n=5$ ), old (filled triangles, $n=20$ ), and young (filled squares, $n=16$ ) B6D2F1 mice underwent allogeneic BMT as described in Methods. Very old B6D2F1 (open circle, $n=3$ ) and old (open triangle, $n=7$ ) mice that received syngeneic BMT served as negative GVHD controls. Very old B6D2F1 recipients had significantly more rapid mortality than old recipients $\left({ }^{* *} P=0.03\right)$, and old recipients died significantly faster than young recipients did $\left({ }^{*} P<0.005\right)$. Syngeneic control mice exhibited $100 \%$ survival during the observation period (circles and triangles). (b) Very old (filled circles, $n=9$ ), old (filled triangles, $n=17$ ), and young (filled squares, $n=17$ ) CBA mice were transplanted from B10.BR donors in the same fashion described above. Very old CBA mice that received syngeneic BMT served as negative GVHD controls (open circle, $n=7$ ). Very old CBA mice had greater mortality than old mice had $(P=0.2)$, and old mice died more quickly than young mice $\left({ }^{*} P=0.01\right)$. Syngeneic mice exhibited $100 \%$ survival during the observation period.

To determine serum levels of LPS, the limulus amebocyte lysate (LAL) assay (BioWhittaker Inc., Walkersville, Maryland, USA) was performed according to the manufacturer's protocol. All units expressed are relative to US reference standard EC-6.

FACS. FITC-, phycoerythrin- (PE-), and allophycocyanin-conjugated $\mathrm{mAbs}$ against mouse antigens (CD45.1, CD3ع, CD4, CD8, CD11b, CD11c [HL3], CD40, CD80, CD86, and I-A ${ }^{b}$ ) were purchased from $\mathrm{BD}$ Pharmingen. The analysis was performed as described previously (14). Briefly, cells were incubated with $\mathrm{mAb} 2.4 \mathrm{G} 2$ for 15 minutes at $4^{\circ} \mathrm{C}$ and then with the relevant FITC-, PE-, or allophycocyanin-conjugated $\mathrm{mAb}$ for 30 minutes at $4^{\circ} \mathrm{C}$. Cells were washed twice with $0.2 \%$ BSA in PBS and fixed with PBS and $1 \%$ paraformaldehyde. Three-color flow cytometry was performed with an EPICS Elite ESP cell sorter (Beckman Coulter Inc., Miami, Florida, USA). For analysis of cell division, splenic $\mathrm{T}$ cells were labeled with carboxyfluorescein succinimidyl ester (CFSE; Molecular Probes Inc., Eugene, Oregon, USA) as described (15) and then transferred into irradiated recipients. For intracellular cytokine staining, splenocytes were harvested 4 days after transplantation. Cells were incubated for 4 hours with PMA-ionomycin (BD Pharmingen) and brefeldin $\mathrm{A}$ at $37^{\circ} \mathrm{C}$. Then cells were permeabilized with the Cytofix/Cytoperm Kit from Pharmingen (San Diego, California, USA) and subsequently stained with PE-conjugated IFN- $\gamma \mathrm{mAb}$. Flow cytometry was conducted by gating for the designated cell populations. 
Splenic $\mathrm{T}$ cell depletion. $\mathrm{CD} 4^{+}$and $\mathrm{CD}^{+} \mathrm{T}$ cells were depleted using CD4- and CD8- MicroBeads and the AutoMACS system (Miltenyi Biotec) according to the manufacturer's protocol.

Statistical analysis. The Mann-Whitney U test was used for the statistical analysis of cytokine data, LPS levels, clinical GVHD scores, and histology, whereas the Cox regression test was used to analyze survival data. $P<0.05$ was considered statistically significant.

\section{Results}

Enhanced GVHD mortality and morbidity in aged recipients of allogeneic BMT. The effect of recipient age on the severity of GVHD was evaluated in well-established murine models of GVHD elicited by both major and minor histocompatibility antigen differences between donors and recipients. Young ( 2 months old), old (14-16 months), and very old (22 months) B6D2F1 $\left(\mathrm{H}-2^{\mathrm{b} / \mathrm{d}}\right)$ mice were irradiated with $11 \mathrm{~Gy}$ TBI and transplanted with $5 \times 10^{6} \mathrm{BM}$ cells and $2 \times 10^{6}$ splenic T cells from B6 ( $\left.\mathrm{H}-2^{\mathrm{b}}\right)$ donors, as described in Methods. As shown in Figure 1a, recipient age is a continuous variable with respect to GVHD severity. Severe GVHD developed in very old recipients, with $100 \%$ mortality by day 11 . In old mice, mortality was slightly but significantly delayed $(P=0.03)$, and it was further delayed in young recipients of allogeneic BMT, $50 \%$ of which were alive on day $50(P<0.01)$. All old and very old recipients of syngeneic BMT survived the entire observation period, ruling out conditioning-related toxicity as a cause of death. Clinical GVHD scores were assessed by a standard scoring system that sums changes in five parameters (see in Methods). Scores were significantly greater in very old recipients compared with old recipients $(7.2 \pm 0.1$ versus $5.2 \pm 0.3$, respectively, $P<0.05)$. Clinical GVHD scores of old mice were also significantly higher compared with those of young mice $(5.2 \pm 0.3$ versus $4.3 \pm 0.1$, respectively, $P<0.01)$. Similar results were observed in a second allogeneic donor/recipient strain combination (B6 $\rightarrow$ B6SJLF1) where old (16 months, $n=9$ ) and young (2 months, $n=6)$ mice were used as recipients. Day 50 survival (55\% in old mice versus $100 \%$ in young mice, $P=0.016)$ and GVHD scores $(3.7 \pm 0.5$ in old mice versus $1.4 \pm 0.2$ in young mice, $P<0.01)$ demonstrated more severe GVHD in old mice at all timepoints.

Increased GVHD with age was also seen in a minor histocompatibility antigen-mismatched mouse model (B10.BR $\rightarrow$ CBA, Figure 1b). Compared with young mice (2-3 months of age), old mice (12-14 months) died significantly more rapidly $(P=0.01)$. All very old mice (22 months) developed more severe GVHD than both other groups and died within 26 days; age was a significant continuous variable with respect to GVHD, according to Cox regression analysis $(P<0.001)$.

Increased GVHD was also observed in old compared with young recipients after a variety of conditioning regimens, including cyclophosphamide alone. B6D2F1 mice were treated with $100 \mathrm{mg} / \mathrm{kg}$ cyclophosphamide on both day -2 and day -1 and transplanted with $5 \times 10^{6}$ B6 BM cells and $2 \times 10^{7}$ B6 spleen cells. Day 40 survival in 16-month-old BMT recipients was significantly
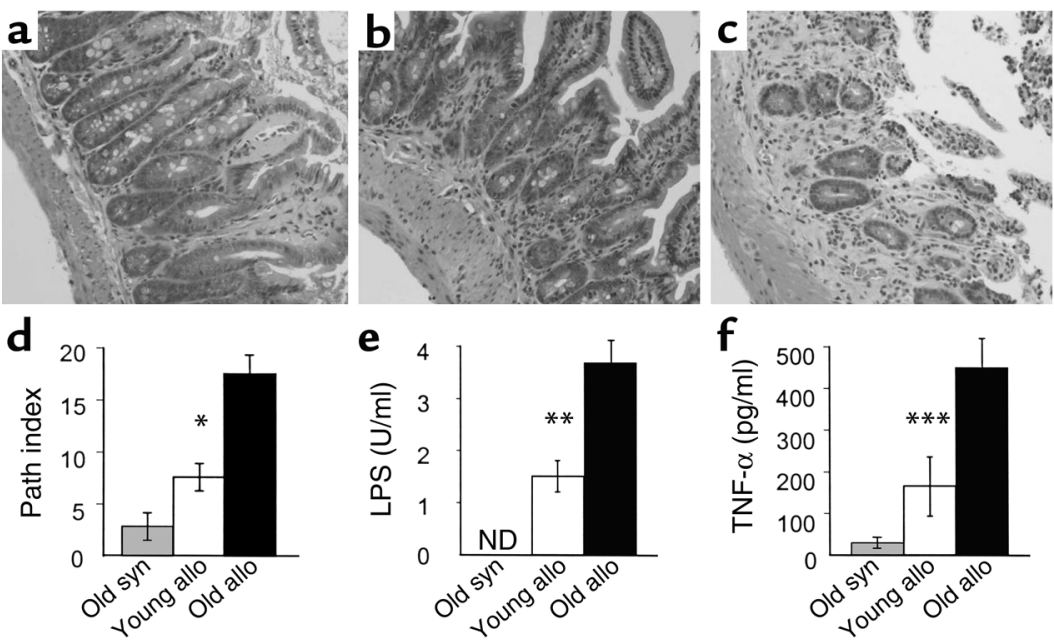

\section{Figure 2}

Age exacerbates Gl tract GVHD and increases serum LPS and TNF- $\alpha$. B6D2F1 mice were transplanted as described in Figure 1 legend. Small bowel histology at day 7 in BMT recipients conditioned with 11 Gy TBI. Coded slides were evaluated for villus blunting, crypt destruction, loss of enterocyte brush border, luminal sloughing of cellular debris, and lamina propria lymphocytic infiltrate. Tissue damage of old syngeneic mice was minimal (a). The small bowel of old allogeneic mice (c) exhibited more severe villus blunting, crypt destruction changes, crypt atrophy, and increased lymphocytic infiltrate than did that of young allogeneic mice (b). Original magnification: $\times 200$. (d) Pathology index. Coded slides from each group (old syngeneic [gray bar], young allogeneic [white bar], and old allogeneic mice [black bar]) were scored for each parameter on a scale of $0-4$ and summed $\left(n=4\right.$ in each group). ${ }^{*} P<0.03$, young versus old allogeneic mice. (e and $\left.\mathbf{f}\right)$ Mice were transplanted as in Figure 1 and serum was obtained by performing heart puncture on day 7 after BMT. LPS (e) and TNF- $\alpha(\mathbf{f})$ data represent the mean \pm SE of 9 young (white bar) and 9 old (black bar) animals ${ }^{*} P<0.01,{ }^{*} * P=0.03$, young versus old allogeneic mice. Data were combined from animals transplanted in two separate experiments. Path index, pathology index; syn, syngeneic; allo, allogeneic. ND, not detected. 

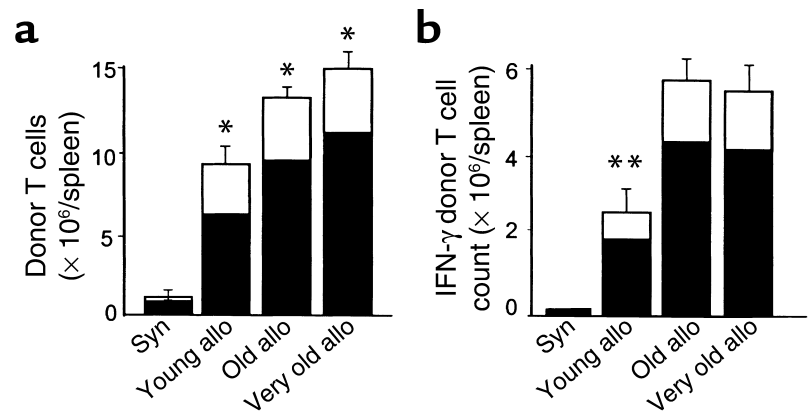

Figure 3

(a) Increased donor $T$ cell response as a function of recipient age. Mice of different ages were transplanted with $5 \times 10^{6} \mathrm{~T}$ cells after radiation with $11 \mathrm{~Gy}$. Splenocytes were harvested on day 4 ( $n=3$ /group). Donor T cell phenotype $\left(\mathrm{CD}^{+}, \mathrm{CD} 8^{+}\right.$, and $\left.\mathrm{CD} 45.1^{+}\right)$ was determined by FACS analysis as described in Methods. Data represent the mean $+\mathrm{SE}$ of $\mathrm{CD} 4^{+}$(black bar) and $\mathrm{CD} 8^{+}$cells (white bar). Age was a significant continuous variable with respect to $C D 4^{+}$donor T cell expansion according to Cox regression analysis ( $\left.{ }^{*} P=0.02\right)$. Data from one of three similar experiments is shown. (b) IFN- $\gamma$ production from donor cells was determined by intracytoplasmic staining of IFN- $\gamma$ after cells were purified by Ficoll density-gradient centrifugation and incubated for 4 hours with PMA, ionomycin, and brefeldin A. ${ }^{*} P<0.002$, young versus old and very old. One of three similar experiments is shown.

decreased compared with that of young mice ( $0 \%$ versus $83 \%, P=0.01$ ), and aged recipients displayed significantly more clinical acute GVHD than young recipients did $(5.5 \pm 0.3$ versus $3.2 \pm 0.2$, respectively, $P<0.01)$. Thus, increased GVHD mortality and morbidity in aged recipients was neither strain- nor conditioning-dependent.

Accelerated GVHD in old mice was confirmed by histopathologic analysis of the small and large intestine in the $\mathrm{B} 6 \rightarrow \mathrm{B} 6 \mathrm{D} 2 \mathrm{~F} 1$ model. Acute GVHD histology is characterized by diffuse apoptosis, lymphocytic infiltrate, brush-border loss, mucosal sloughing into the lumen, epithelial degeneration, and crypt regeneration (Figure 2). Histologic scores of individual criteria were summed to produce a semiquantitative pathology index as previously described (16). Damage to the GI tract was twice as severe in old recipients as in young allogeneic recipients (Figure $2 \mathrm{~d}$ ). Serum levels of LPS and TNF- $\alpha$ were also significantly increased in older recipients, consistent with the pathologic data (Figure 2 , e and $\mathrm{f}$ ). Thus by all clinical, pathologic, and biochemical indices, acute GVHD was worse in old allogeneic recipients than in young allogeneic recipients. Aged host natural killer cells do not cause increased GVHD in aged recipients. Host natural killer (NK) cells are known to decline with age in several mouse strains, and NK cells play an important role in hybrid resistance in the B6 $\rightarrow$ B6D2F1 BMT model $(17,18)$. To exclude the possibility that a decline of NK cell function with age could explain accelerated acute GVHD in old mice, we depleted NK cells of BMT recipients according to a published protocol (19). Mice were treated with $200 \mu \mathrm{g}$ of antiNK1.1 mAbs on days -2 and -1 , which depleted NK1.1 $1^{+}$ cells as measured by FACS (data not shown). At day 0 , mice were irradiated with 11 Gy TBI and transplanted as described above. GVHD mortality in old NK-depleted recipients was significantly higher than in young NK-depleted mice (median survival time, 10 days versus 21 days, respectively; $P=0.01$ ). Clinical GVHD also remained more severe in old mice after NK cell depletion $(6.2 \pm 0.3$ versus $4.6 \pm 0.3$ in young mice, $P<0.01)$. Depletion of NK cells from BMT recipients thus had no impact on the effects of age on GVHD severity.

Enhanced donor $T$ cell responses to host antigens in aged allogeneic BMT. Acute GVHD requires activation of donor $\mathrm{T}$ cells by host APCs (5). We hypothesized that the increased GVHD in old recipients was due to greater donor $\mathrm{T}$ cell activation. We therefore analyzed donor $\mathrm{T}$ cell expansion in the spleens of BMT recipients 4 days after transplant. Using B6.Ly5.2 congenic donors, we observed significantly increased numbers of donor $\mathrm{T}$ cells $\left(\mathrm{CD}^{+}, \mathrm{CD}^{+}, \mathrm{CD} 45.1^{+}\right)$that correlated with advancing recipient age. This increase was mainly due to the increase of donor $\mathrm{CD}^{+} \mathrm{T}$ cells and not $\mathrm{CD}^{+} \mathrm{T}$ cells (Figure 3a; $P=0.02$ ). FACS analysis of donor cells by annexin staining showed no difference in the percentage of apoptotic donor cells in young versus old recipients, ruling out less activated induced cell death in old recipients as a cause for the increased $\mathrm{T}$ cell expansion in aged recipients (15). Flow cytometric analysis of intracellular IFN- $\gamma$, an important cytokine mediator of acute GVHD, showed a twofold increase in the number of IFN- $\gamma$-expressing $\mathrm{CD}^{+}$donor $\mathrm{T}$ cells in the spleens of old recipients. The number of IFN- $\gamma$-producing donor $\mathrm{T}$ cells was very similar in old and very old allogeneic recipients compared with young allogeneic recipients (Figure $3 b ; P=0.002$ ).

$\mathrm{CD}^{+}$donor cells are responsible for increased acute $G V H D$ in old mice. Depletion of $\mathrm{CD}^{+}\left(\right.$but not $\left.\mathrm{CD} 8^{+}\right)$donor $\mathrm{T}$ cells prevents lethal GVHD across a full MHC disparity in parent $\rightarrow$ F1 BMT mouse models $(20,21)$. To evaluate the role of donor $\mathrm{CD}^{+} \mathrm{T}$ cells in severity of GVHD in old recipients, we depleted either $\mathrm{CD}^{+}$or $\mathrm{CD}^{+} \mathrm{T}$ cells from donor $\mathrm{B} 6$ splenic $\mathrm{T}$ cells with $\mathrm{mAb}$ coupled to magnetic beads using the AutoMACS system as described in Methods. FACS analysis showed that the purity of the resulting donor $\mathrm{T}$ cells was always greater than $95 \%$. Young and old B6D2F1 recipients were transplanted with $5 \times 10^{6} \mathrm{~T}$ cell depleted (TCD) BM cells together with $1 \times 10^{6} \mathrm{CD}^{+}$or $\mathrm{CD}^{+} \mathrm{T}$ cells. Depletion of $\mathrm{CD} 4^{+} \mathrm{T}$ cells from the donor-cell inoculum effectively eliminated GVHD mortality, and both young and old recipients of $\mathrm{CD}^{+}$cells survived the entire observation period (Figure 4). By contrast, old recipients of $\mathrm{CD} 4^{+} \mathrm{T}$ cells experienced significantly greater mortality than did young recipients $(\mathrm{P}<0.001)$. $\mathrm{CD}^{+}$donor $\mathrm{T}$ cells are therefore the principal effectors in acute GVHD severity in this parent $\rightarrow \mathrm{F} 1$ mouse model and are responsible for the increased GVHD in old recipients.

Increased T cell stimulation by APCs from aged mice in vivo and in vitro. Inflammatory stimuli such as LPS and TNF can accelerate allogeneic $\mathrm{T}$ cell responses (22-24). We therefore asked whether enhanced donor $T$ cell respons- 


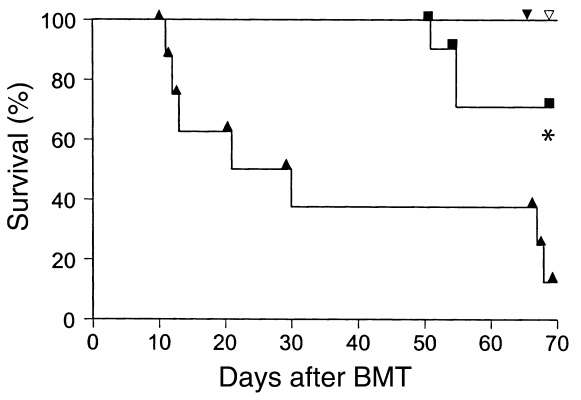

Figure 4

$\mathrm{CD}^{+}$donor T cells induce GVHD mortality in old allogeneic recipients. Old (triangles, $n=8$ ) and young (squares, $n=10$ ) B6D2F1 mice received $11 \mathrm{~Gy} \mathrm{TBI}$ and were injected with $5 \times 10^{6} \mathrm{TCD} \mathrm{BM}$ and $1 \times 10^{6}$ $\mathrm{CD}^{+}$splenic $\mathrm{T}$ cells from allogeneic B6 mice. ${ }^{*} P<0.005$, old versus young mice. Filled inverted triangle and open inverted triangle represent old $(n=8)$ B6D2F1 and young $(n=10)$ B6D2F1 mice, respectively, receiving $5 \times 10^{6} \mathrm{TCD} B M$ cells and $1 \times 10^{6} \mathrm{CD} 8^{+}$donor T cells.

es in old recipients were secondary to increased susceptibility of the GI tract to TBI conditioning that would allow translocation of inflammatory stimuli to the systemic circulation. To investigate this question, donor $\mathrm{T}$ cell expansion was analyzed after transfer of $5 \times 10^{7} \mathrm{~B} 6$ splenocytes to nonirradiated B6D2F1 recipients without radiation-induced gut damage. To exclude the impact of NK cells in this nonirradiated model, we depleted NK cells with anti-NK1.1 mAb as described above. Donor T cell expansion was twofold greater in the spleens of nonirradiated old recipients, due primarily to expansion of $\mathrm{CD}^{+} \mathrm{T}$ cells (Figure $5 \mathrm{a}$ ). We next compared the ability of APCs from freshly isolated $\mathrm{B} 6 \mathrm{D} 2 \mathrm{~F} 1$ splenocytes to stimulate naive $\mathrm{B} 6$ responders in vitro. As shown in Figure 5, b-d, B6 T cells proliferated more rapidly and produced greater amounts of IFN- $\gamma$ and IL-2 in response to B6D2F1 stimulator cells from old animals than from young animals. APCs from very old mice also showed greater stimulation of allogeneic responses than did APCs from old mice. Prolif- eration in B10.BR anti-CBA mixed lymphocyte reaction (MLR) (which is a $\mathrm{CD8}^{+} \mathrm{T}$ cell-dependent minor antigen $\mathrm{H}$ mismatched system) (20) was also increased with old stimulators $(4,732 \pm 370$ versus $8,735 \pm 1,010 \mathrm{cpm}$, $P<0.001)$. FACS analysis of the spleen cells did not show increases in the numbers of $\mathrm{CD} 11 \mathrm{~b}^{+}$macrophages or $\mathrm{CD} 11 \mathrm{c}^{+} \mathrm{DCs}$ with increasing age (data not shown).

Since dendritic cells are the most potent APCs (25), we next compared the allostimulatory capacity of BMderived DCs from young versus old mice. DCs were generated in a standard fashion as described in Methods. DCs from old mice induced greater proliferation of allogeneic T cells than did DCs from young mice (Figure 5e). FACS analysis of these cells showed that costimulatory molecules, including CD80, CD86, and CD40, were not consistently increased, but MCH II expression of DCs was consistently upregulated with increasing age (mean fluorescence intensity: 12 versus 29 versus 41 units). TNF- $\alpha$ and IL-12, known to play important roles in augmenting alloreactive $\mathrm{T}$ cell response, were also produced in significantly greater amounts by old DCs than by young DCs after LPS stimulation (Figure 5 , f and g). All mice tested negative for infectious pathogens, ruling out increased viral burden and expression of neoantigens as the cause for increased allostimulation by old APCs.

Aged APCs are sufficient to increase GVHD severity. To investigate whether aged APCs were sufficient to induce more severe GVHD, we generated BM chimeras in which cells of hematopoietic lineages were derived from old mice, and nonhematopoietic cells (including all epithelial GVHD targets) were from young mice. Young B6D2F1 mice ( 2 months of age) were irradiated with $11 \mathrm{~Gy}$, followed by injection of $5 \times 10^{6} \mathrm{BM}$ cells from either young ( 2 months) or old (18 months) syngeneic $\mathrm{B} 6 \mathrm{D} 2 \mathrm{~F} 1$ mice. This BMT procedure produced $100 \%$ donor engraftment by week 8 after transplant (data not shown). Four months later, old $\rightarrow$ young and young $\rightarrow$ young chimeric mice were used as recipients

\section{Figure 5}

Increased T cell responses to old host APCs. (a) Nonirradiated young and old B6D2F1 mice were injected with $5 \times 10^{7}$ splenic lymphocytes from B6.Ly5.2 donors for expansion studies. Spleens were harvested on day 4. Donor T cell phenotype (CD4 ${ }^{+}, \mathrm{CD}^{+}$, and $\left.\mathrm{CD} 45.1^{+}\right)$ was determined by FACS analysis as described in Methods. (b-d) Young splenic T cells from B6 mice were cultured with irradiated spleen cells from either young B6D2F1 or old B6D2F1 animals. Proliferation and IL-2 and IFN- $\gamma$ production were measured as described in Methods. (e) BM-derived DCs were irradiated and cultured with $1 \times 10^{5} \mathrm{~T}$ cells from B6 mice as described in Methods. $\mathrm{T}$ cell proliferation was determined by $\left[{ }^{3} \mathrm{H}\right]$ thymidine incorporation. $P<0.01$, allogeneic T cell responses to old DCs (filled squares) versus young DCs (open squares). (f and $\mathbf{g}$ ) TNF- $\alpha$ and IL-12 p40 secretion from DCs stimulated with $0.1 \mu \mathrm{g} \mathrm{LPS} / \mathrm{ml}$ for 4 hours (TNF- $\alpha$ ) or 24 hours (IL-12 p40). Each graph represents one of three similar experiments. ${ }^{*} P=0.03,{ }^{*} P<0.01$.
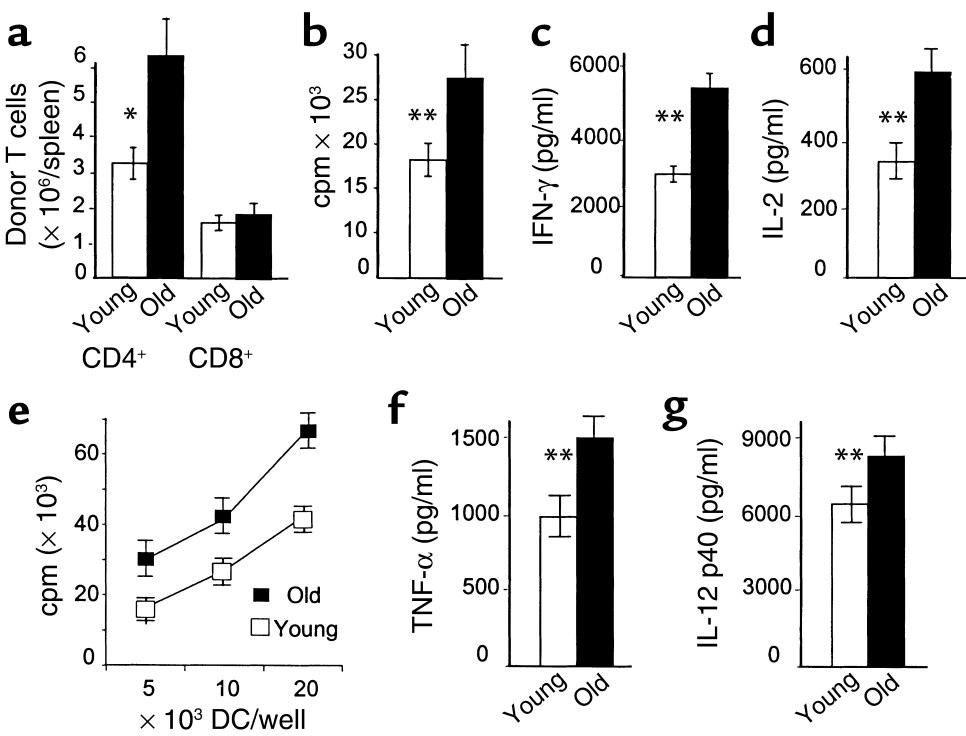

f

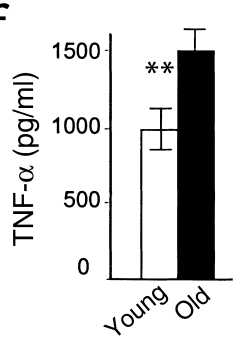

g

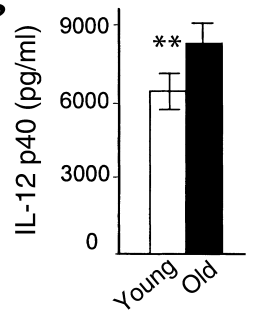



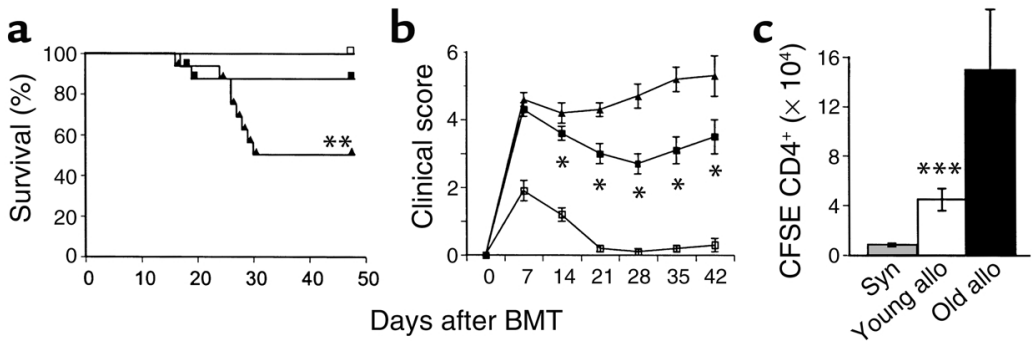

\section{Figure 6}

Increased severity of GVHD in old APC chimeric mice. Young B6D2F1 mice received 11 Gy $\mathrm{TBI}$ and were injected with $5 \times 10^{6} \mathrm{BM}$ cells from young ( 2 months old) or old (18 months) B6D2F1 mice. After 3 months for hematopoietic engraftment and APC repopulation, chimeric mice were irradiated again with 7.5 Gy and injected with $5 \times 10^{6} \mathrm{~B} 6 \mathrm{BM}$ cells and $2 \times 10^{6}$ splenic T cells from B6 mice. (a) Old $\rightarrow$ young chimeric mice (triangles, $n=16$ ) had significantly more rapid mortality than did young $\rightarrow$ young chimeras (squares, $n=16$ ). ${ }^{*} P<0.003$ by log rank test. (b) Clinical GVHD score was measured as described in Methods. ${ }^{*} P<0.05$, old donors versus young donors. GVHD scores are shown as mean $\pm \mathrm{SE}$. (c) B6 donor T cells were labeled with CFSE as described in Methods and injected into chimeric recipients after 7.5 Gy TBI. Splenocytes were harvested and pooled ( $n=3 /$ group) on day 3 after BMT and labeled with anti-CD4 as described in Methods. ${ }^{*} * P<0.02$. One experiment representative of two similar experiments is shown.

of allogeneic BMT. We hypothesized that if increased age of APCs was the primary cause of increased GVHD severity, then old $\rightarrow$ young chimeras injected with old BM would have old APCs and should develop more intense disease than young $\rightarrow$ young chimeras, despite the identical age of the GVHD target tissues. Chimeric mice were transplanted with $2 \times 10^{6}$ splenic $T$ cells and $5 \times 10^{6} \mathrm{BM}$ cells from B6 donors after 7.5 Gy TBI. The lower dose of 7.5 Gy was chosen to minimize conditioning toxicity while remaining myeloablative. As shown in Figure 6 , a and b, old $\rightarrow$ young chimeras developed significantly more severe GVHD than did young $\rightarrow$ young chimeras, as measured by survival and clinical score $(P<0.003)$. Although there was almost no mortality in young $\rightarrow$ young chimeras receiving young APCs (probably due to the decreased TBI conditioning), GVHD was present, as evidenced by the significantly increased clinical scores. Flow cytometric analysis confirmed $100 \%$ donor engraftment in both groups after the second BMT, ruling out mixed chimerism as a reason for reduced GVHD in young $\rightarrow$ young chimeras. Analysis of CFSE-labeled donor $\mathrm{T}$ cell response in vivo at day 3 after BMT confirmed greater $\mathrm{CD}^{+}{ }^{+}$donor $\mathrm{T}$ cell expansion (Figure $6 \mathrm{c}$ ). The percentage of cells undergoing at least two cell divisions in the old $\rightarrow$ young chimeras was higher than in the young $\rightarrow$ young chimeras ( $74 \%$ versus $65 \%$ ), indicating increased $\mathrm{T}$ cell response to old APCs in vivo.

In vitro naive $\mathrm{B} 6 \mathrm{~T}$ cell responders proliferated more rapidly in response to freshly isolated splenocytes from old chimera B6D2F1 mice than from young chimeric mice in MLR $(29,853 \pm 2,066$ versus $18,363 \pm 1,614$, $P<0.001)$. These data indicate that old APCs are sufficient to induce an increased response from allogeneic donor T cells and cause more severe GVHD, irrespective of the age of the recipient target organs.

\section{Discussion}

Large numbers of patients with hematologic malignancies are in their seventh decade, and many of these diseases might be treated effectively by allogeneic BMT, but patients of this age are not usually considered for such therapy because of the high risk of GVHD and other treatment-related toxicities $(6,26$, 27). Recently, Bryson et al. demonstrated increased GVHD in aged recipients that were conditioned for allogeneic BMT by TBI (7). We have confirmed and extended these observations in several mouse models, wherein all clinical, pathologic, and biochemical indices showed acute GVHD to be worse in old recipients. Our studies also suggest a hitherto unsuspected mechanism for this association: increased allogenicity of APCs with age.

The primary hypotheses regarding increased GVHD in elderly recipients involved the altered function of the immune system of old recipients, increased load of bacterial and viral antigens with age, and reduced repair capacity of aged tissues. The process of thymic involution (decreased thymic size and function) that occurs with increasing age has long been thought to be related to increased GVHD in the elderly (28). Mackall et al. showed that the capacity to produce new $\mathrm{CD} 4^{+} \mathrm{T}$ cells expressing CD45RA following chemotherapy is inversely correlated with patient age (29). Decreased thymic function in aged recipients might amplify acute GVHD by reducing host resistance to donor $T$ cell expansion. As a result of thymic involution, the export of naive $T$ cells from the thymus decreases and consequently shifts the ratio of naive $T$ cells to memory $\mathrm{T}$ cells. This shift is associated with a decline in proliferation and IL-2 production in response to mitogens (30-32). This decline in $\mathrm{T}$ cell function with age could be considered a type of acquired immunodeficiency that makes older patients more susceptible to a GVH reaction. GVHD itself also damages the thymus, resulting in a loss of negative selection and emergence of host-reactive clones (33-35). This loss of central self-tolerance has important implications for chronic GVHD, but its role in acute GHVD may be less direct. For example, thymectomy of young recipients has no effect on GVHD (36).

NK cell activity also declines with age, although the data in humans are inconsistent $(17,37)$. NK cells are known to play an important role in hybrid resistance to engraftment, which would be operative in the $\mathrm{B} 6 \rightarrow$ B6D2F1 combination examined in our study (19). To control for this possibility, we depleted NK cells with an anti-NK1.1 Ab, but the differences in GVHD between old and young recipients remained. Thus the senescence 
of the recipient immune system does not appear to play a primary role in amplifying GVHD in these models.

A second possibility for more severe GVHD in aged recipients is the increase in viral or bacterial antigenic exposure with age. Clinical acute GVHD is associated with viral infections, particularly cytomegalovirus, and viral antigens are well-known targets for $\mathrm{T}$ cell responses (38-41). This phenomenon is an unlikely explanation for our observations because all recipients have been housed in specific pathogen-free conditions their entire lives, and all animals tested were negative for the entire panel of infectious pathogens.

A second issue related to exposure of infectious agents relates to bacterial gut flora. Bacterial LPS crosses damaged gut mucosa, amplifying systemic GVHD in animal models, and blockade of LPS or selective bowel decontamination can reduce clinical GVHD and improve survival $(14,42-44)$. Some clinical studies suggest that bacterial overgrowth in the small bowel increases with age, although these studies are small and may suffer from selection bias related to age $(45,46)$. Even if such bacterial loading holds possible clinical relevance, the $\mathrm{BM}$ chimera experiments rule out this mechanism as an explanation for more severe GVHD in old mice in this experimental model.

An issue related to the titer of viral and/or bacterial antigens is the decreased ability of aged tissue to repair. Several studies show increased cardiotoxicity, neurotoxicity, and mucositis after chemotherapy in the elderly (47). The molecular mechanisms for such decreased repair may involve telomere shortening, which correlates with the remaining life span of somatic cells (48). The reduced ability of aged GI mucosa to repair itself may have an effect similar to bacterial overgrowth in the GI tract - more LPS and inflammatory mediators can translocate to the systemic circulation in aged mice because repair is slower, thus amplifying cytokine dysregulation and the severity of GVHD. Again, the differences observed between young BM chimeras and old BM chimeras effectively rule out this explanation. All epithelial target tissues were the same age in the chimeric recipients in our study, whereas only the hematopoietic system, including APCs, differed in age. We cannot formally conclude that these possible risk factors - senescence of the recipient immune system, increased exposure to viral and bacterial antigens, and decreased tissue repair in aged recipients - do not contribute to the increased clinical GVHD in elderly recipients. But our study has identified a hitherto unexpected, additional mechanism for this phenomenon: increased allostimulation by aged APCs. The importance of host APCs in acute GVHD has recently been underscored by Shlomchik et al. (5). Other studies have suggested that older APCs can enhance T cell responses of both humans and mice $(49,50)$. Sidman and colleagues showed that MHC class I and class II expression increase with age, causing greater response in MLRs (50). This observation is consistent with our data showing that APCs from aged mice caused greater allogene- ic responses both in vitro and in vivo. Both TNF- $\alpha$ and IL-12 production from DCs increased significantly with advancing age after LPS stimulation. TNF- $\alpha$ is known to play an important role in augmenting alloreactive $T$ cell responses $(24,51)$, and several groups have shown that TNF- $\alpha$ production increases with advancing age of human monocytes and murine macrophages (52-54), although information regarding altered function of DCs with aging is scarce (55). IL-12 induces Th1 cytokines and is able to stimulate the development of acute $\operatorname{GVHD}(56,57)$.

$\mathrm{CD}^{+}$donor $\mathrm{T}$ cells are primarily responsible for acute GVHD in the $\mathrm{B} 6 \rightarrow \mathrm{B} 6 \mathrm{D} 2 \mathrm{~F} 1$ model studied here $(20,21)$. Increased acute GVHD mortality in older recipients was dependent on $\mathrm{CD}^{+}$donor $\mathrm{T}$ cells, underscoring the potential impact of MHC class II upregulation of APCs in old recipients and its contribution to the acceleration of acute GVHD. We demonstrated a moderate increase in the number of $\mathrm{CD}^{+}$ donor $\mathrm{T}$ cells undergoing cell division in the chimera recipients at day 3 after BMT, but we did not detect a decrease in apoptosis, suggesting that donor $\mathrm{T}$ cells may accumulate in aged recipients.

The decreased mortality in both age groups after transfer of an isolated $\mathrm{CD}^{+}$subset is probably related to the lack of synergy observed when both $T$ cell subsets induced acute GVHD. It is also important to note that increased GVHD severity in old mice was observed in the $\mathrm{B} 10 . \mathrm{BR} \rightarrow \mathrm{CBA}$ model, wherein $\mathrm{CD}^{+} \mathrm{T}$ cells are the principal mediators of GVHD (20). Studies are currently in progress to determine whether a similar increase in MHC class I expression in aged recipients can amplify acute GVHD mediated by $\mathrm{CD}^{+}$donor T cells.

Our experiments cannot determine whether the increase in APC function in old BM chimeras is due to differences in older stem cells or whether long-lived APC progenitors present in the BM inoculum also contribute to this process. To the extent that enhanced APC capacity of older stimulators pertains to all antigens, it is possible that it may contribute to the higher incidence of autoimmune disease with increased age.

Better understanding of GVHD pathophysiology in aged recipients and the role of APCs in this process will hopefully lead to improved strategies to reduce this intractable problem and thereby make allogeneic BMT available to the large number of older patients who might benefit from this therapy.

\section{Acknowledgments}

The authors wish to thank Kenneth R. Cooke for helpful discussions. This work was supported by the Deutsche Krebshilfe (R. Ordemann) and by NIH grants RO3 AG-19943-01 (R. Hutchinson) and CA39542 (J.L.M. Ferrara).

\footnotetext{
1. Antin, J.H., and Ferrara, J.L.M. 1992. Cytokine dysregulation and acute graft-versus-host disease. Blood. 80:2964-2968.

2. Ferrara, J.L. 2000. Pathogenesis of acute graft-versus-host disease: cytokines and cellular effectors. J. Hematother. Stem Cell Res. 9:299-306.

3. Rus, V., Svetic, A., Nguyen, P., Gause, W.C., and Via, C.S. 1995. Kinetics of Th1 and Th2 cytokine production during the early course of acute and
} 
chronic murine graft-versus-host disease. J. Immunol. 155:2396-2406. 4. Kichian, K., Nestel, F.P., Kim, D., Ponka, P., and Lapp, W.S. 1996. IL-12 p40 messenger RNA expression in target organs during acute graft-versus-host disease. Possible involvement of IFN-gamma. J. Immunol. 157:2851-2856.

5. Shlomchik, W.D., et al. 1999. Prevention of graft versus host disease by inactivation of host antigen-presenting cells. Science. 285:412-415.

6. Sullivan, K., Storb, R., Buckner, D., and Fefer, A. 1989. Graft-versus-host disease as adoptive immunotherapy in patients with advanced hematologic neoplasms. N. Engl. J. Med. 320:828-834.

7. Bryson, J.S., et al. 1997. Enhanced graft-versus-host disease in older recipient mice following allogeneic bone marrow transplantation. Bone Marrow Transplant. 19:721-728.

8. Teshima, T., et al. 1999. IL-11 separates graft-versus-leukemia effects from graft-versus-host disease after bone marrow transplantation. J. Clin. Invest. 104:317-325.

9. Cooke, K.R., et al. 1996. An experimental model of idiopathic pneumonia syndrome after bone marrow transplantation. I. The roles of minor $\mathrm{H}$ antigens and endotoxin. Blood. 88:3230-3239.

10. Cooke, K.R., et al. 1998. TNF- $\alpha$ production to lipopolysaccharide stimulation by donor cells predicts the severity of experimental acute graftversus-host disease. J. Clin. Invest. 102:1882-1891.

11. Inaba, K., et al. 1992. Generation of large numbers of dendritic cells from mouse bone marrow cultures supplemented with granulocyte/ macrophage colony stimulating factor. J. Exp. Med. 176:1693-1702.

12. Fields, R.C., et al. 1998. Comparative analysis of murine dendritic cells derived from spleen and bone marrow. J. Immunother. 21:323-339.

13. Teshima, T., et al. 2001. Tumor cell vaccine elicits potent antitumor immunity after allogeneic T-cell-depleted bone marrow transplantation. Cancer Res. 61:162-171.

14. Hill, G.R., et al. 1997. Total body irradiation and acute graft versus host disease. The role of gastrointestinal damage and inflammatory cytokines. Blood. 90:3204-3213.

15. Reddy, P., et al. 2001. Interleukin-18 regulates acute graft-versus-host disease by enhancing Fas-mediated donor T cell apoptosis. J. Exp. Med. 194:1433-1440.

16. Hill, G.R., and Ferrara, J.L. 2000. The primacy of the gastrointestinal tract as a target organ of acute graft-versus-host disease: rationale for the use of cytokine shields in allogeneic bone marrow transplantation. Blood. 95:2754-2759.

17. Albright, J.W., and Albright, J.F. 1983. Age-associated impairment of murine natural killer activity. Proc. Natl. Acad. Sci. USA. 80:6371-6375.

18. Mikael, N., et al. 1994. Genetic control of the decline of natural killer cell activity in aging mice. Growth Dev. Aging. 58:3-12.

19. Bix, M., et al. 1991. Rejection of class I MHC-deficient haemopoietic cells by irradiated MHC-matched mice. Nature. 349:329-231.

20. Korngold, R., and Sprent, J. 1990. T cell subsets in graft-versus-host disease. In graft-versus-host disease: immunology, pathophysiology, and treatment S.J. Burakoff, H.J. Deeg, J. Ferrara, and K. Atkinson, editors. Marcel Dekker Inc. New York, New York, USA. 31-50.

21. Sykes, M., Harty, M.W., Szot, G.L., and Pearson, D.A. 1994. Interleukin2 inhibits graft-versus-host disease-promoting activity of CD4+ cells while preserving CD4- and CD8-mediated graft-versus-leukemia effects. Blood. 83:2560-2569.

22. Vella, A.T., et al. 1997. CD28 engagement and proinflammatory cytokines contribute to $\mathrm{T}$ cell expansion and long term survival in vivo. J. Immunol. 158:4714-4720.

23. Pape, K.A., Khoruts, A., Mondino, A., and Jenkins, M.K. 1997. Inflammatory cytokines enhance the in vivo clonal expansion and differentiation of antigen-activated CD4+ T cells. J. Immunol. 159:591-598.

24. Hill, G.R., et al. 2000. The p55 TNF-alpha receptor plays a critical role in T cell alloreactivity. I. Immunol. 164:656-663.

25. Steinman, R. 1991. The dendritic cell system and its role in immunogenicity. Annu. Rev. Immunol. 9:271-296.

26. Trimble, E.L., et al. 1994. Representation of older patients in cancer treatment trials. Cancer. 74:2208-2214.

27. Kernan, N., et al. 1993. Analysis of 462 transplantations from unrelated donors facilitated by the national marrow donor program. N. Engl. J. Med. 328:593-602.

28. Storb, R., and Thomas, E.D. 1985. Graft-versus-host disease in dog and man: the Seattle experience. Immunol. Rev. 88:215-238.

29. Mackall, C.L., et al. 1995. Age, thymopoiesis, and CD4+ T-lymphocyte regeneration after intensive chemotherapy. N. Engl. J. Med. 332:143-149.

30. Roberts-Thomson, I.C., Whittingham, S., Youngchaiyud, U., and Mackay, I.R. 1974. Ageing, immune response, and mortality. Lancet. 2.368-370.

31. Lerner, A., Yamada, T., and Miller, R.A. 1989. Pgp-1hi T lymphocytes accumulate with age in mice and respond poorly to concanavalin A. Eur J. Immunol. 19:977-982.
32. Utsuyama, M., et al. 1992. Differential age-change in the numbers of CD4+CD45RA+ and CD4+CD29+ T cell subsets in human peripheral blood. Mech. Ageing Dev. 63:57-68.

33. van den Brink, M.R., Moore, E., Ferrara, J.L., and Burakoff, S.J. 2000. Graft-versus-host-disease-associated thymic damage results in the appearance of $\mathrm{T}$ cell clones with anti-host reactivity. Transplantation. 69:446-449.

34. Holländer, G.A., Widmer, B., and Burakoff, S.J. 1994. Loss of normal thymic repertoire selection and persistence of autoreactive $\mathrm{T}$ cells in graft versus host disease. J. Immunol. 152:1609-1617.

35. Fukushi, N., et al. 1990. Thymus: a direct target tissue in graft-versushost reaction after allogeneic bone marrow tranpslantation that results in abrogation of induction of self-tolerance. Proc. Natl. Acad. Sci. USA. 87:6301-6305.

36. Ferrara, J.L.M., and Burakoff, S.J. 1990. The pathophysiology of acute graft-versus-host disease in a murine bone marrow transplant model. In Graft-versus-host disease: immunology, pathophysiology, and treatment. S.J. Burakoff, H.J. Deeg, J. Ferrara, and K. Atkinson, editors. Marcel Dekker Inc. New York, New York, USA. 9-29.

37. Solana, R., and Mariani, E. 2000. NK and NK/T cells in human senescence. Vaccine. 18:1613-1620.

38. Grundy, J.E., Shanley, J.D., and Shearer, G.M. 1985. Augmentation of graft-versus-host reaction by cytomegalovirus infection resulting in interstitial pneumonitis. Transplantation. 39:548-553.

39. Ringden, O. 1990. Viral infections and graft-versus-host disease. In Graftversus-host disease: immunology, pathophysiology, and treatment. S.J. Burakoff, H.J. Deeg, J. Ferrara, and K. Atkinson, editors. Marcel Dekker Inc. New York, New York, USA. 467-486.

40. Hagglund, H., et al. 1995. Risk factors for acute graft-versus-host disease in 291 consecutive HLA-identical bone marrow transplant recipients. Bone Marrow Transplant. 16:747-753.

41. Riddell, S.R., and Greenberg, P.D. 1995. Principles for adoptive T cell therapy of human viral diseases. Annu. Rev. Immunol. 13:545-586.

42. Nestel, F.P., Price, K.S., Seemayer, T.A., and Lapp, W.S. 1992. Macrophage priming and lipopolysaccharide-triggered release of tumor necrosis factor alpha during graft-versus-host disease. J. Exp. Med. 175:405-413.

43. Cooke, K.R., et al. 2001. LPS antagonism reduces graft-versus-host disease and preserves graft-versus-leukemia activity after experimental bone marrow transplantation. J. Clin. Invest. 107:1581-1589.

44. Beelen, D.W., et al. 1992. Evidence that sustained growth suppression of intestinal anaerobic bacteria reduces the risk of acute graft-versus-host disease after sibling marrow transplantation. Blood. 80:2668-2676.

45. Lewis, S.J., Potts, L.F., Malhotra, R., and Mountford, R. 1999. Small bowel bacterial overgrowth in subjects living in residential care homes. Age Ageing. 28:181-185.

46. Lipski, P.S., Kelly, P.J., and James, O.F. 1992. Bacterial contamination of the small bowel in elderly people: is it necessarily pathological? Age Ageing. 21:5-12.

47. Balducci, L., and Extermann, M. 1997. Cancer chemotherapy in the older patient: what the medical oncologist needs to know. Cancer. 80:1317-1322.

48. Harley, C.B., Futcher, A.B., and Greider, C.W. 1990. Telomeres shorten during ageing of human fibroblasts. Nature. 345:458-460.

49. Castle, S.C., Uyemura, K., Crawford, W., Wong, W., and Makinodan, T. 1999. Antigen presenting cell function is enhanced in healthy elderly. Mech. Ageing Dev. 107:137-145.

50. Sidman, C.L., et al. 1987. Increased expression of major histocompatibility complex antigens on lymphocytes from aged mice. Proc. Natl. Acad. Sci. USA. 84:7624-7628.

51. Kitabayashi, A., et al. 1995. Granulocyte colony stimulating factor downregulates allogeneic immune response by posttranscriptional inhibition of tumor necrosis factor- $\alpha$ production. Blood. 86:2220-2227.

52. Rink, L., Cakman, I., and Kirchner, H. 1998. Altered cytokine production in the elderly. Mech. Ageing Dev. 102:199-209.

53. Fagiolo, U., et al. 1993. Increased cytokine production in mononuclear cells of healthy elderly people. Eur. J. Immunol. 23:2375-2378.

54. Chorinchath, B.B., Kong, L.Y., Mao, L., and McCallum, R.E. 1996. Ageassociated differences in TNF- $\alpha$ and nitric oxide production in endotoxic mice. J. Immunol. 156:1525-1530.

55. Saurwein-Teissl, M., Romani, N., and Grubeck-Loebenstein, B. 2000. Dendritic cells in old age-neglected by gerontology? Mech. Ageing Dev. 121:123-130

56. Via, C.S., Rus, V., Gately, M.K., and Finkelman, F.D. 1994. IL-12 stimulates the development of acute graft-versus-host disease in mice that would normally develop chronic, autoimmune graft-versus-host disease. J. Immunol. 153:4040-4047.

57. Williamson, E., Garside, P., Bradley, J.A., and Mowat, A.M. 1996. IL-12 is a central mediator of acute graft-versus-host disease in mice. J. Immunol. 157:689-699. 